\title{
Gerhardt Stenger, Diderot. Le combattant de la liberté
}

\section{Eszter Kovács}

\section{(2) OpenEdition}

\section{Journals}

\section{Édition électronique}

URL : http://journals.openedition.org/studifrancesi/2164

DOI : 10.4000/studifrancesi.2164

ISSN : 2427-5856

\section{Éditeur}

Rosenberg \& Sellier

\section{Édition imprimée}

Date de publication : 1 avril 2014

Pagination : 146

ISSN : 0039-2944

\section{Référence électronique}

Eszter Kovács, « Gerhardt Stenger, Diderot. Le combattant de la liberté », Studi Francesi [En ligne], 172 (LVIII | I) | 2014, mis en ligne le 01 avril 2014, consulté le 10 décembre 2020. URL : http://

journals.openedition.org/studifrancesi/2164; DOI : https://doi.org/10.4000/studifrancesi.2164

Ce document a été généré automatiquement le 10 décembre 2020.

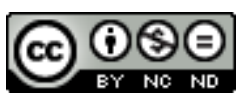

Studi Francesi è distribuita con Licenza Creative Commons Attribuzione - Non commerciale - Non opere derivate 4.0 Internazionale. 


\title{
Gerhardt Stenger, Diderot. Le combattant de la liberté
}

\author{
Eszter Kovács
}

\section{RÉFÉRENCE}

GERHARDT STENGER, Diderot. Le combattant de la liberté, Paris, Perrin, 2013, pp. 790.

1 Gerhardt Stenger a publié sa biographie de Diderot à l'occasion du tricentenaire de la naissance du Philosophe. Parmi les biographies parues avant 2013, celle d'Arthur Wilson (publiée en 1972 en anglais, traduite en français en 1985) reste toujours une référence. Une nouvelle biographie était pourtant nécessaire, surtout parce que l'image de Diderot a beaucoup changé depuis les années 1970. L'œuvre est mieux connue, plus en vue dans les recherches dix-huitièmistes, on a beaucoup publié sur Diderot depuis le bicentenaire de sa mort en 1984, mais il faudrait intégrer les résultats et les interprétations récents dans un ouvrage de synthèse.

2 Pourquoi dans une biographie? Notre perception de la littérature reste, malgré tout, souvent "biographique". Pourtant, dans une approche plus nuancée, il ne s'agit pas d'expliquer l'œuvre à partir de la vie de l'auteur mais de mettre en parallèle les deux. On peut d'ailleurs interpréter une vie comme une œuvre, ce qui est un exercice plus raffiné que l'approche biographique traditionnelle. Les biographies qui se veulent "modernes" font plutôt lire l'œuvre qu'informer le lecteur uniquement sur la vie de l'auteur.

3 Après le titre modeste du livre de Wilson (Diderot), celui plus orienté de Laurent Versini (Denis Diderot, alias Frère Tonpla, 1994) et de Raymond Trousson (Denis Diderot ou le vrai Prométhée, 2005), Stenger intitule son livre Diderot. Le combattant de la liberté. Ce qui projette un parti pris: celui de considérer le rôle de Diderot dans certains débats des Lumières, actuels même de nos jours.

4 Le livre se compose de quatre parties, dont chacune se compose de huit chapitres. Le dernier chapitre sert de conclusion. L'auteur souligne dans l'avant-propos que l'œuvre 
de Diderot a été découverte et construite par la postérité. Dans la première partie, intitulée «Naissance d'un philosophe», Stenger s'occupe de la ville natale, de la famille et des premières années parisiennes de Diderot. Il présente ses traductions et ses premières œuvres philosophiques. On trouve dans cette partie l'analyse détaillée des Pensées philosophiques, de la Lettre sur les aveugles et de la Lettre sur les sourds et muets.

5 La deuxième partie, intitulée "L'encyclopédiste», présente l'histoire et l'enjeu de l' Encyclopédie, les écrits philosophiques personnels de Diderot durant cette période, son emprisonnement à Vincennes. Stenger parle des amis ayant eu une influence sur Diderot (Grimm, d'Holbach, Rousseau) et de sa relation avec Sophie Volland, qui reste toujours énigmatique. Il inclut dans cette partie le drame bourgeois et la morale athée de Diderot.

6 La partie «Le bon, le vrai et le beau» propose une analyse de la Religieuse en vue de sa Préface-annexe et de l'Éloge de Richardson. Pour Diderot, l'illusion de la vérité est de première importance dans la fiction et dans la représentation picturale. «L'ordre de la nature» est un chapitre central, consacré surtout au Rêve de d'Alembert et aux Éléments de physiologie. En observant la fiction de Diderot, Stenger s'occupe en détail de l'art de la mystification et de la théorie du modèle idéal: la fiction est, chez Diderot, en quelque sorte, la transposition du réel.

7 La partie «Le bourgeois révolutionnaire» s'occupe de la pensée politique de Diderot, centrée autour des notions de la liberté et de la propriété (qui veut dire aussi la propriété de sa personne). Stenger observe le rapport de Diderot avec sa fille et analyse sa réflexion sur la condition des femmes. Il fait une lecture comparée des trois contes, à savoir Ceci n'est pas un conte, Mme de La Carlière et le Supplément au Voyage de Bougainville. Le Neveu de Rameau est un texte-clé dans cette partie: Stenger considère les différentes interprétations possibles du dialogue. Il démontre également que Diderot est souvent partial dans la Réfutation d'Helvétius: il s'agit de deux approches différentes du matérialisme, alors que la Réfutation de Diderot a fait longtemps oublier Helvétius. Stenger s'occupe également du voyage en Russie et des ouvrages destinés à Catherine II. Il examine de plus près certaines contributions à l'Histoire des deux Indes. Dans le dernier chapitre, il se concentre sur le contexte politique et moral de la fin de l'œuvre, surtout à propos des deux éditions de l'Essai sur Sénèque (la deuxième ayant pour titre l'Essai sur les règnes de Claude et de Néron). Il constate les inconséquences historiques de l'Essai mais souligne que Sénèque devient le modèle idéal en morale, en quelque sorte similaire à l'idéal esthétique. Le livre se termine par une réflexion sur le destin des manuscrits et des éditions de Diderot.

8 Les analyses de Stenger sont situées dans le contexte historique et philosophique de l'époque. Son objectif est de faire comprendre Diderot, parcourir la vie et l'œuvre, s'arrêter et mieux considérer certaines périodes et certaines questions. Quelques sujets sont particulièrement au centre, par exemple le matérialisme et l'athéisme de Diderot, sa morale, les débats et combats de l'époque. Les analyses sont contrastées, les citations bien choisies, les extraits et les commentaires se complètent. Stenger examine la continuité de différentes périodes chez Diderot en utilisant les meilleurs spécialistes ainsi que ses propres résultats. Le lecteur peut sentir la sympathie, voire une véritable passion du chercheur envers l'œuvre traitée. 